\title{
ASSOCIATION OF HOUSEHOLD FOOD INSECURITY WITH ACADEMIC PERFORMANCE AND NUTRITIONAL STATUS OF FISHERMAN'S SCHOOL-AGED CHILDREN IN TERENGGANU, MALAYSIA
}

\author{
NUR SHAFIKAH HASHIM ${ }^{1}$, ASMA` ALI ${ }^{*}$, KHAIRIL SHAZMIN KAMARUDIN ${ }^{1}$, \\ HAYATI MOHD YUSOF ${ }^{1}$, NOOR SALIHAH ZAKARIA ${ }^{1}$, NORHASMAH SULAIMAN ${ }^{2}$ \\ and ZALILAH MOHD SHARIFF ${ }^{2}$ \\ ${ }^{1}$ Department of Food Science, Faculty of Fisheries and Food Science, \\ Universiti Malaysia Terengganu, 21030 Kuala Nerus, Malaysia \\ ${ }^{2}$ Department of Nutrition and Dietetics, Faculty of Medicine and Health Sciences, \\ Universiti Putra Malaysia, 43400 Serdang, Selangor, Malaysia \\ *E-mail: asma.ali@umt.edu.my
}

Accepted 28 September 2021, Published online 30 November 2021

\begin{abstract}
This study was conducted to establish the relationship between household food insecurity (via Household Food Insecurity Access Scale), academic performance (overall class position through School Exam Analysis System), and the nutritional status (BMI-for-age and height-for-age determination) of fishermen's children in Terengganu. This was a cross-sectional study involving 101 fishermen's children aged 7 to 11 years old. The data were analyzed using the Chi-square test. The result shows that the prevalence of children with food insecurity was $43.2 \%$. It was found that $24.2 \%$ of fishermen's children were good at the academic level while $51.3 \%$ were moderate and $24.2 \%$ were poor. BMI prevalence for children who were normal $69.3 \%$ and remaining was $6.9 \%$ obese, $2.0 \%$ overweight, $12.9 \%$ thinness, and $8.9 \%$ severe thinness. For height-for-age, $8.9 \%$ were stunting, normal $88.1 \%$, tallness $2.0 \%$, followed by severely stunted $1.0 \%$. There is no association found between household food insecurity and academic performance $\chi^{2}(1, n=101)=1.891, p=0.169$. There is also no association found between household food insecurity with BMI-for-age $\chi^{2}(1, n=101)=1.105, p=0.293$ and height-for-age, $p>0.05$ (with Fischer exact value $=0.093$ ). Further studies must be carried out to produce further evidence of household food insecurity for fishermen in other Malaysian states, to prevent this group from being ignored.
\end{abstract}

Key words: Academic performance, fishermen's children, household food insecurity, Malaysia, nutritional status

\section{INTRODUCTION}

In recent decades, household food insecurity has been one of the key issues for the vulnerable community, particularly for the children of fishermen, to meet their basic needs such as food (Nursabrina et al, 2018). Many researchers have paid significant attention because increasing household food insecurity raises the risk of poor academic performance and lower cognitive function (Fiese et al., 2018; Asma' et al., 2020; Chin et al., 2020; Teh et al., 2020) as well as social-emotional challenges, poor dietary intake (Ahmad et al, 2020) and psychosocial issues among children (Ali Naser et al.,

* To whom correspondence should be addressed.
2014). Thus, children are exposed to many adverse effects, particularly in terms of their academic performance (Faught et al., 2017; Esfandiari et al., 2018; Zhang \& Yang, 2019) and nutritional status (Pei et al., 2018; Drysdale et al., 2020; Ieiri et al., 2020) due to high household food insecurity.

Food insecurity is one factor that leads to a higher prevalence of underweight, stunting, and wasting. This is because of poor household conditions resulting in lower consumption of foods rich in energy and nutrients that affect improvements in children's health. A study has shown that in Kelantan - one of the top five states in Malaysia receiving food basket assistance (Ministry of Health Malaysia, 2000), the prevalence of stunting was $69.0 \%$, underweight was $63.4 \%$, with wasting of 
$40.0 \%$ considered high, indicating inadequate diets in the early years of children (Cheah et al., 2012). The economic status of fishing communities in Malaysia remains relatively poor, despite significant improvements in the fishing sector regarding technology and landings (Amin \& Salim, 2012). In Peninsular Malaysia, especially on the east coast, fishermen are experiencing a high rate of poverty (Aisyah et al., 2014). According to statistics, Terengganu has 7,038 extremely poor households, while Kelantan has 9,391 and Sabah has 13,837 (Rhoumah, 2016). According to Mario et al. (2018) study, many fishermen's children are malnourished because of natural disasters such as typhoons and tsunamis, and a lack of economic capacity. Extreme incidents harm children's welfare. Apart from that, children from low-income families typically have limited access to food and nutrition. These two factors, however, are not the only ones. Apart from that, the quality of food consumed, food availability, household size, guardians' and household head's literacy contribute to the nutritional status outcome. Another study, led by Saleha et al. (2017), focuses on Indonesian children's nutritional status. The study discovered a substantial prevalence of underweight among children living along the coast.

Several studies have shown a significant relationship between household food insecurity, academic performance, and nutritional status. However, little study has been done on the food insecurity of households, academic performance, and nutritional status of fishermen's children. This study has thus shown whether a relationship exists in Terengganu between household food insecurity, academic performance, and the nutritional status of fishermen's children.

\section{MATERIALS AND METHODS}

\section{Research design}

This cross-sectional study was conducted for two months, from July to September 2019, among fishermen's children in Kuala Terengganu and Kuala Nerus, two districts in the state of Terengganu. The study involved 101 fishermen's children aged between 7 and 11 years and their mothers, who had no physical disability, good health status, and the ability to speak Malay. The research's human ethical approval was obtained from the Universiti Malaysia Terengganu (UMT) Human Research Ethics Committee with reference number JKEPM/2019/37. Mothers are informed of the study and invited to participate in it. Written consent is obtained from mothers before data collection. Based on the Cochran formula, given the $95 \%$ confidence interval, $5 \%$ margin of error, and the expected proportion of food insecurity in Kuala Nerus, Terengganu was $98.8 \%$ (Nursabrina et al., 2018), the required sample size for this study was 101 fishermen's children and their mothers.

\section{Research instruments}

This study's research tool was a set of a survey questionnaire that was distributed to the respondents. The survey questionnaire consists of four vital parts, part 1 Socio-demographic question: information on mother's age, religion, ethnicity, mothers' level of education, marital status, household size, number of children, monthly household income, occupation, house status, recipient of financial support, recipient of food assistance and source of financial aid. Next is Part 2 on the Household Food Insecurity Access Scale (HFIAS), where the household access component towards household food insecurity in a local setting was conducted. The validated Malay translated-HFIAS (Maarof, 2018) consists of nine questions asked with a four-week (30-day) recall period. The mother was asked an occurrence question, which was whether the condition in the question happened in the past four weeks (yes or no). If the respondent answers "yes" to an occurrence question, a frequency-ofoccurrence question was asked to determine whether the condition occurred in the past four weeks rarely (once or twice), sometimes (three to ten times), or often (more than ten times). Two main things were determined by HFIAS, which were; 1 - the total summative score of HFIAS ranged from 0 to 27 points ( 1 point $=$ Rarely (once or twice in the past four weeks), 2 points $=$ Sometimes (three to ten times in the past four weeks) and 3 points $=$ Often (more than ten times in the past four weeks)) and 2 Categorization of the total summative score of HFIAS into either Category 1 (food secure), Category 2 (mildly food insecure), Category 3 (moderately food insecure) or Category 4 (severely food insecure). The categorization follows Coates (2004) and Nursabrina et al. (2018). Part 3 is on academic performance to indicate the level of academic performance of fishermen's children based on their school position. Academic performance was measured by grading fishermen's children in the class and their overall class position excluding children 7 years of age due to no examination results at that time. The School Exam Analysis System was used to check the fisherman's children's overall position permitted by their mother. A percentile basis was referred to determine fishermen's children's academic achievement: $<25$ th percentile - good ranking in class; 25 th-50th percentile - moderate ranking in class; $>75$ th percentile - poor ranking in class. Part 4 is the anthropometric measurement of the weight and height of the fishermen's children for 
BMI-for-age and height-for-age determination. The children's weight and height were measured using an electronic weighing scale (Tanita Bioelectrical Impedance Analysis BC-541, Japan) and SECA portable stadiometer 225 (SECA, Hamburg, Germany), respectively. The respondents were asked to step on the weighing scale and maintain a straight posture; measurements were then taken to the nearest $0.1 \mathrm{~kg}$. The fishermen's children were instructed by the researcher to step on the stadiometer, standing upright in the middle. The fishermen's children's heads, shoulders, buttocks, knees, and heels touch the board. The measurement was announced to the nearest $0.1 \mathrm{~cm}$. The measurement taken was analyzed using a WHO Anthro version 3.2.2 software to assess the children's nutritional status in z-score (BMI-for-age and height-for-age).

\section{Data collection}

The mother-child pair were approached through a home visit and asked about their willingness to take part. Once agreed, written consent is obtained from the mother before data collection. Mothers were required to answer Part 1 Socio-demographic questions and Part 2, Household Food Insecurity Access Scale, assisted by the researcher. The researcher instructed the children to answer Part 3 of the question, which was about the previous final examination's academic performance. Next, children's body weight and height were determined and categorized based on BMI-for-age and height-for-age in WHO Reference 2007. The respondents were given a token of appreciation before the researcher left.

\section{Data analysis}

Version 20 of the SPSS was used to analyze and report the data collected. The normality test is used to check the distribution of normality. Descriptive analysis was used to determine the demographic, socio-economic profile, distribution of household food insecurity status, academic performance, and nutritional status of fishermen's children. The Chisquare at $p<0.05$ was used to assess the association between household food insecurity, academic performance, and the nutritional status of fishermen 's children. However, Fisher's Exact Test was used when more than $20 \%$ of the expected value in each cell is greater than 5 was attained.

\section{RESULTS}

Table 1 shows that most parents of children who were willing to participate were between 40 and $49(50.5 \%)$. About half of the fishermen $(62.4 \%)$ and their wives had secondary education (74.3\%).
Approximately $88.1 \%$ of household revenues were below RM1500, and $41.6 \%$ of household size was between 6-8 people per household. More than half of the fishermen's families had 3-5 children (55.4\%). The majority of mothers were housewives (72.3\%). About $67.3 \%$ of the fishermen's households live together with their parents/in-laws or in a house that the landowner gave them to live in. Approximately $56.4 \%$ of the families received financial assistance. More than half of those surveyed received financial support from Majlis Agama Islam Dan Adat Melayu Terengganu (MAIDAM) but received no food help. Approximately $49.5 \%$ of those interviewed received financial aid. Some fishermen received Jabatan Kebajikan Masyarakat (JKM) financial support (5.0\%), while $2.0 \%$ received financial support from others. About $43.6 \%$ received no financial support from any source, which is a bit worrying since there is no fixed income for fishermen.

In Table 2, the HFIAS prevalence distribution among fishermen's households in Kuala Terengganu and Kuala Nerus is shown. Shariff et al.'s study (2008) stated that $50 \%$ of households experienced food insecurity and reported hunger for children due to larger households, more children, and moms as housewives. The most protuberant aspect of the current data is that most respondents in the food security category accounted for $56.4 \%$, but about $43.5 \%$ found food insecurity. Specifically, of the $43.5 \%$ of food insecurity: $17.8 \%$ were mild food insecurity, followed by $19.8 \%$ moderate food insecurity and $5.9 \%$ severe food insecurity. About half of those surveyed reported food insecurities, which is not a good phenomenon. This study showed that, although this was not a monsoon season, most respondents reacted more frequently to their severe food conditions.

Table 3 shows the academic distribution of the children of fishermen based on the percentile position. Around $51.3 \%$ of fishing children had moderate performance, followed by $24.4 \%$ for good performance, and $24.2 \%$ had a poor academic performance.

Table 4 shows the nutritional status of Kuala Terengganu and Kuala Nerus children of the fishermen. Nutritional status is one of the vital factors suitable to indicate whether children have food insecurity or food security. This is because adequate food and nutrition play a significant role in children's physiology, growth, and development. The results obtained for BMI-for-age indicate that children who were normal $69.3 \%$, obese $6.9 \%$, overweight $2.0 \%$, thinness $12.9 \%$, and severe thinness $8.9 \%$. This data shows that the thinness percentage was far above obesity and overweight. The reported percentage for stunting was $8.9 \%$, followed by $1.0 \%$ of severely stunted. 
Table 1. Socio-demographic profile of fishermen's children mother $(n=101)$

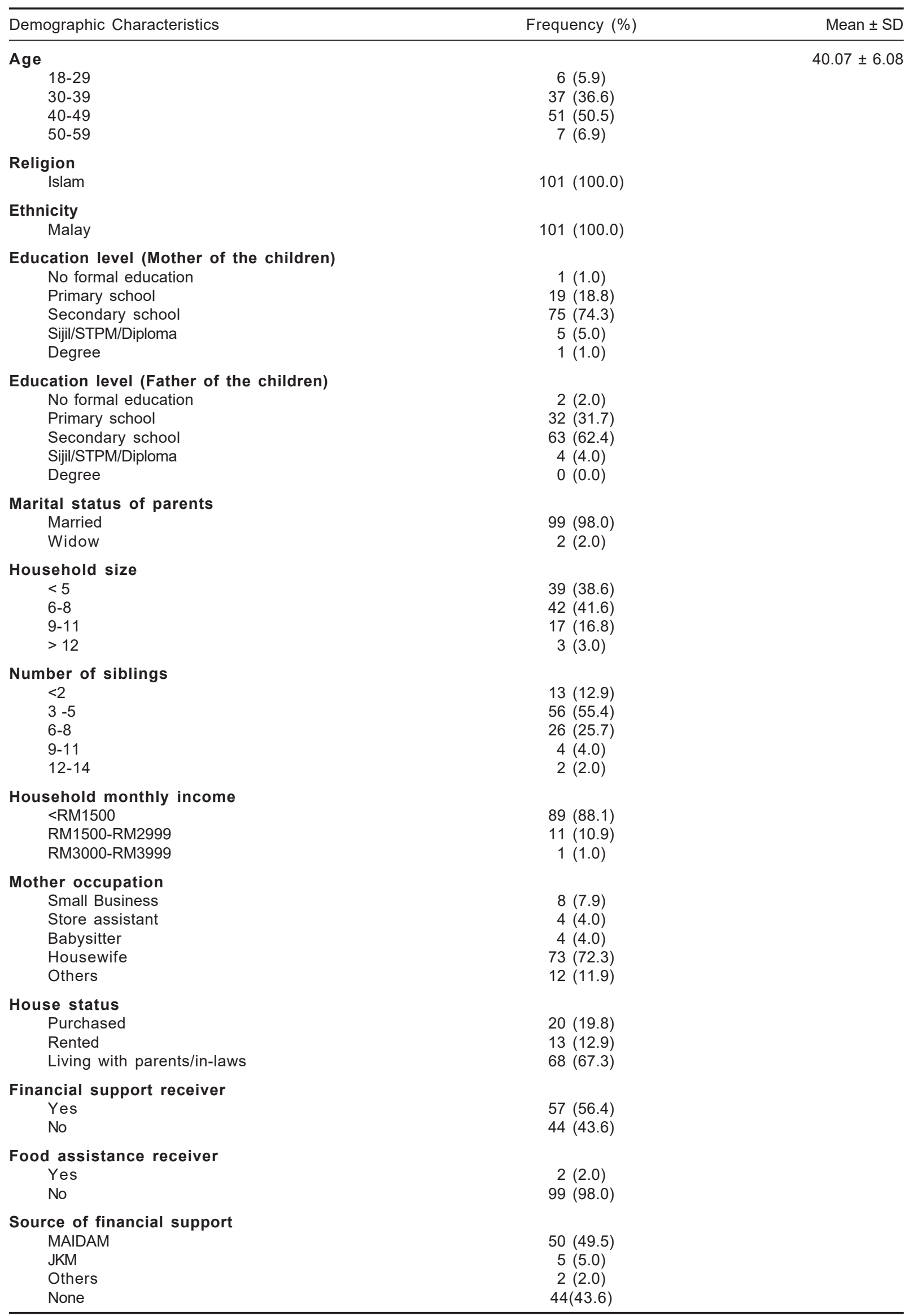

MAIDAM = Majlis Agama Islam Dan Adat Melayu Terengganu. JKM = Jabatan Kebajikan Masyarakat. 
Table 2. Household Food Insecurity Access Scale (HFIAS) prevalence among fishermen's households $(n=101)$

\begin{tabular}{lc}
\hline HFIAS Prevalence & Frequency \\
\cline { 2 - 2 } & $n(\%)$ \\
\hline Food secure & $57(56.4)$ \\
Mildly Food Insecure & $18(17.8)$ \\
Moderately Food Insecure & $20(19.8)$ \\
Severely Food Insecure & $6(5.9)$ \\
\hline
\end{tabular}

Table 3. Rank percentile of academic performance of fishermen's children based on position in class $(n=78) \ddagger$

\begin{tabular}{lccr}
\hline Position ranking in class based on percentile* & Indicator & Frequency, $n(\%)$ & Median (IQR) \\
\hline$<25^{\text {th }}$ percentile & Good & $19(24.4)$ & $53.9(49.6)$ \\
$25^{\text {th }}-75^{\text {th }}$ percentile & Moderate & $40(51.3)$ & \\
$>75^{\text {th }}$ percentile & Poor & $19(24.2)$ & \\
\hline
\end{tabular}

*The lower the percentile, the better the position ranking in class

¥The analysis involved $n=78$, excluding children 7 years of age due to no examination results at that time.

Table 4. Nutritional status of fishermen's children $(n=101)$

\begin{tabular}{lccc}
\hline Nutritional status & Characteristics & Frequency (\%) & Median (IQR) \\
\hline BMI-for-age (z-score) & & & $-1.03(1.90)$ \\
& Obesity & $7(6.9)$ & \\
& Overweight & $2(2.0)$ & \\
& Normal & $70(69.3)$ & \\
& Thinness & $13(12.9)$ & $-0.59(0.12)$ \\
Height-for-age (z-score) & Severe Thinness & $9(8.9)$ & \\
& & & \\
\hline
\end{tabular}

\section{Association of household food insecurity with academic performance and nutritional status of fishermen's children}

The Chi-Square test showed no significant association between household food insecurity and nutritional status in the BMI-for-age and height-forage $\mathrm{z}$ scores at $\chi^{2}(1, n=101)=1.105, p=0.293$ and $(p=0.057)$ respectively. The Chi-Square test showed no significant association between household food insecurity and academic performance at $\chi^{2}(1, n=101)$ $=1.891, p=0.169$, respectively as shown in Table 5 .

\section{DISCUSSION}

This study on the distribution of household food insecurity is consistent with the results of Maarof (2018) and Jomaa et al. (2019), which reported food insecurity in Kelantan and Lebanon at 40.0 to $49.3 \%$. It is also alleged that overcrowding, low parental education, and low wages make them live below the poverty line and can not afford to buy enough food for one family member, particularly a household with more children (Jomaa et al., 2019). A previous study conducted by Farhadian et al. (2015) in the Sabah community showed that it is sometimes difficult to get enough food because the community does not have enough money and a source of food. It may also be explained that low-income households are likely to have high living costs because of unforeseen expenses (Shariff \& Khor, 2008; Mamat et al., 2019).

Moreover, fishermen's performance may be children were inadequate in academic performance because of their parents' low socioeconomic status, which resulted in low interest in children's education 
Table 5. Association between household food insecurity, fishermen's children nutritional status, and academic performance $(n=101)$

\begin{tabular}{|c|c|c|c|c|}
\hline \multirow{2}{*}{ Nutritional Status } & \multicolumn{2}{|c|}{ Level of food security } & \multicolumn{2}{|c|}{ Pearson Chi-Square } \\
\hline & Food Secure $n(\%)$ & Food Insecure $n(\%)$ & $x^{2}$ & $p$-value \\
\hline \multicolumn{5}{|l|}{ BMI-for-age } \\
\hline Normal & $35(34.7)$ & $32(31.7)$ & $1.105^{\mathrm{a}}$ & 0.293 \\
\hline Others & 14 (13.9) & $20(19.8)$ & & \\
\hline \multicolumn{5}{|l|}{ Height-for-age } \\
\hline Normal & 47 (46.5) & $44(43.6)$ & & $0.093^{b}$ \\
\hline Others & $2(2.0)$ & $8(7.9)$ & & \\
\hline \multicolumn{5}{|c|}{ Academic performance } \\
\hline Good & $33(42.3)$ & $26(33.3)$ & $1.891^{\mathrm{C}}$ & 0.169 \\
\hline Poor & $14(17.9)$ & $5(6.4)$ & & \\
\hline
\end{tabular}

${ }^{*}$ Chi-square significant at $p<0.05$

a 0 cells $(0.0 \%)$ have an expected count less than 5 . The minimum expected count is 16.50 .

b1 cells $(25.0 \%)$ have an expected count less than 5 (use fisher exact test value after creating $2 \times 2$ dummy table).

${ }^{c} 0$ cells $(0.0 \%)$ have an expected count of less than 5 . The minimum expected count is 7.55 .

tThe analysis involved $n=78$, excluding children 7 years of age due to no examination results at that time.

(Hanafi, 2008; Poh et al., 2019). Therefore, poor academic performance at school, where the undernourished or poor life, can harm the overall development of children (Shariff et al., 2000, Poh et al., 2019). A study by Tsai and Liu (2013) mentioned that family socioeconomic status and the parent-child relationship are positively correlated with student achievement. Most parents have a low educational level, which may also be a factor in their having less interest in their children's education, which may cause the parents to not know how to help their children. This can reduce parent-child interaction and, thus, affect children's achievement.

One major factor that could indicate if children are food insecure or secure is their nutritional status assessment. Adequate food and nutrition play a key role in children's bodies, which play a role in physiology, growth, and development. Wong et al. (2014) have reported a higher percentage of underweight (about 45.3\%) when households have a larger sibling size, which means they will experience pressure in the economy to feed each family member. Thus, some parents would easily neglect their children when they are in a bigger family. This study is consistent with the studies carried out by Whye Lian et al. (2012), Jomaa et al. (2019), and KhanKhattak and Ali, (2010), which demonstrate that fishermen's children are malnourished because of deficiencies in micronutrients and macronutrients. One possible reason for this could be that food with low-calorie consumption is consumed because of the economic conditions that re-elected nutritious foods' buying power. A study by Pek Geik (2016) in Gua Musang, Kelantan, found that $76.2 \%$ of stunting is much higher for children under the age of five. This can be explained by the fact that most of them are still fed by their mothers. In contrast, a study by Chong et al. (2016) indicated that children over seven years old had less stunting in their food because they could find and eat. Still, stunting occurs because they have an irregular eating pattern and sometimes skip meals because they spend extended periods at school. Furthermore, this could be because children in rural areas, such as fishing children, often come from lower-income families with low food expenses, making it impossible to eat all three main meals daily, leading to reduced food intake (Mutisya et al., 2015).

This finding runs counter to previous studies' results, which suggest that household food insecurity is linked to children's nutritional status. Food insecurity has been a possible determinant that causes malnutrition in children, especially in families with low incomes who live in rural communities, since they often have food shortages. Multiple macronutrients and micronutrient deficiencies were present in most malnourished children, consistent with other studies (Donnen et al., 1996; Khor, 2003; Ahmed et al., 2012). Compared with the recommended nutrient intake (RNI) of Malaysia, the dietary intakes were inadequate in energy and vitamin A. It was highly reported among malnourished children in Kelantan, Malaysia, where they mainly had a low intake of staple foods, especially rice, noodles, and bread. The low-calorie intake could be due to inadequate access to food, poor feeding practices, and frequent illness (Wong et al., 2014). The household-level of food insecurity is growing by saying that Malaysia is one of the countries facing malnutrition (Ali Naser et al., 2014) and diet-related diseases (Ministry of Health Malaysia, 2005). Children in food-secure households are less likely than children in food-insecure 
households to be underweight, chronically energyefficient, and wasted (Abdulrahman et al., 2016). Previous research also indicated that household food insecurity was significantly related to children's stunting and undergrowth status. Still, wasting did not show that the consumption of expensive food items decreased initially, followed by drop-in portion size and, ultimately, food frequency (Ali Naser et al., 2014). However, this recent study was unable to find any link between household food insecurity and the nutritional status of fishing children.

This study shows that academic performance is not associated with fishers' children's household food insecurity. The previous study shows that poor academic performance in school could be explained by having food insecurity, where they score low on intelligence and achievement tests (Fiese et al., 2018). Food insecurity can cause certain nutrients to be taken low. For children's cognitive development, nutrients such as vitamin D, zinc, iodine, and folate are essential. This is one factor that generally contributes to poor school outcomes among children in disadvantaged communities (Shariff et al., 2000). The lack of a food source also hinders intellectual development.

Moreover, some fishermen's children helped their parents ensure they had enough food, whether they went fishing or doing some small business. Thus, they were exhausted from focusing on homework and studying, which led to poor performance (Chong et al., 2016). Meanwhile, in Ghana, school children make money by fishing and not going to school regularly (Live \& Poipoi 2012). Thus, work time impairs the studies of the children of fishermen. Children will probably find it challenging to balance their time between helping their parents and concentrating on their education. Parents were highly vulnerable to anxiety and helplessness, control loss, family dysfunction, and psychological impairment in food-insecure households (Ali Naser et al., 2014). It could also make it hard for children to concentrate on education and choose to help their parents.

The present study only considered the context of fishermen's children in Terengganu. Thus, these study findings need to be interpreted cautiously. Future research in this field would be of great help if the sampling location could be extended to Malaysia's other states to be more representative of the fishermen's population overall. This study was done to raise awareness of how important it is to maintain a good supply of food to ensure the healthy growth and development of children, especially among fishermen's children. Besides, it will provide baseline information on academic performance and the nutritional status of fishermen's children in Terengganu. Lastly, to give a better understanding of household food insecurity with the academic performance and nutritional status of fishermen's children.

\section{CONCLUSION}

This study aimed to ascertain the relationship between household food insecurity, academic performance, and the nutritional status of children of fishermen in Kuala Terengganu and Kuala Nerus. This study discovered no correlation between household food insecurity and the academic performance or nutritional status of fishermen's children. Despite its exploratory nature, this study added some details to the status of household food insecurity, academic performance, and nutritional status of fishermen's children in Terengganu, Peninsular Malaysia’s East Coast.

\section{ACKNOWLEDGEMENTS}

The authors would like to express their sincere gratitude to all respondents for their participation, full cooperation, and patience during the study. This study was funded under the Fundamental Research Grant Scheme for Research Acculturation of Early Career Researchers (FRGS - RACER): RACER/1/2019/ SKK06/UMT//1. This study is part of a larger study "Risk assessments of low cognitive performance among fishermen's children in Terengganu, Malaysia".

\section{REFERENCES}

Ahmad, M.H., Selamat, R., Salleh, R., Majid, N.L.A., Zainuddin, A.A., Bakar, W.A.M.A. \& Aris, T. 2020. Food insecurity situation in Malaysia: Findings from Malaysian Adult Nutrition Survey (MANS) 2014. Malaysian Journal of Public Health Medicine, 20(1): 167-174.

Ahmed, T., Roy, S., Alam, N. \& Hossain, M.I. 2012. Determinants of undernutrition in children under 2 years of age from rural Bangladesh. Indian Pediatric, 49(10): 821-824.

Aisyah, D., Omar, K. \& Mokhtar, N.F. 2014. Social welfare development program among coastal community (SPKMP) in Kuala Terengganu: A preliminary assessment on the performance of the program. Elixir International Journal, 74: 27065-27071.

Ali Naser, I., Jalil, R., Wan Muda, W.M., Wan Nik, W.S., Mohd Shariff, Z. \& Abdullah, M.R. 2014. Association between household food insecurity and nutritional outcomes among children in Northeastern of peninsular Malaysia. Nutrition Research and Practice, 8(3): 304-311. 
Asawa, K., Pujara, P., Thakkar, J.P., Pandya, B.G., Sharma, A.R., Pareek, S., Tak, A., Tak, M. \& Maniar, R. 2014. Assessment of intelligence quotient among schoolchildren of fishermen community of Kutch, Gujarat, India. International Maritime Health, 65(2): 73-78.

Asma', A., Wagimin, N.N., Zakaria, N.S., Kamarudin, K.S. \& Yusof, H.M. 2020. Diet quality and cognitive performance of fishermen's children in selected region of Terengganu, Malaysia: A cross-sectional study. Malaysian Applied Biology, 49(4): 173-180.

Cheah, W.L., Wan Muda, W.A., Mohd Hussin, Z.A., \& Thon, C.C. 2012. Factors associated with undernutrition among children in a rural district of Kelantan, Malaysia. Asia-Pacific Journal of Public Health, 24(2): 330-342.

Chin, K.J., Asma', A., Yusof, H.M., Churak, P. \& Latiffah, K. 2020. Does dietary adequacy reflect the cognitive performance of children? A study among the homeless children in Klang Valley, Malaysia. IIUM Medical Journal Malaysia, 19(3): 55-62.

Chua, H.S., Asma, A., Noor Salihah, Z. \& Hayati, M.Y. 2018. Assessment of diet quality and its association with nutritional status among fishermen's children in Terengganu. Malaysian Applied Biology, 47(6): 137-144.

Chong, K.H., Wu, S.K., Noor Hafizah, Y., Bragt, M.C.E. \& Poh, B.K. 2016. Eating habits of Malaysian children: Findings of the South East Asian Nutrition Surveys (SEANUTS). AsiaPacific Journal of Public Health, 28: 59S-73S.

Donnen, P., Brasseur, D., Dramaix, M., Vertongen, F., Ngoy, B., Zihindula, M. \& Hennart, P. 1996. Vitamin A deficiency and protein-energy malnutrition in a sample of pre-school age children in the Kivu Province in Zaire. European Journal of Clinical Nutrition, 50(7): 456-461.

Drysdale, R.E., Bob, U. \& Moshabela, M. 2020. Coping through a drought: The association between child nutritional status and household food insecurity in the district of iLembe, South Africa. Public Health Nutrition, 24(5):1052-1065.

Esfandiari, S., Omidvar, N., Eini-Zinab, H., Doustmohammadian, A. \& Amirhamidi, Z. 2018. Associations among food insecurity, academic performance, and weight status in primary schoolchildren in Tehran, Iran: A cross-sectional study. Journal of Nutrition Education and Behavior, 50(2): 109-117.

Farhadian, A., Chan, V. \& Farhadian, H. 2015. Addressing household food insecurity using the Household Food Insecurity Access Scale (HFIAS) in a poor rural community in Sabah, Malaysia. International Journal of Humanities and Social Science Invention, 4(8): 89-100.
Faught, E., Williams, P., Willows, N., Asbridge, M. \& Veugelers, P. 2017. The association between food insecurity and academic achievement in Canadian school-aged children. Public Health Nutrition, 20(15): 2778-2785.

Fiese, B.H., Gundersen, C., Koester, B. \& Washington, L. 2018. Household food insecurity: Serious concerns for child development and commentaries. Social Policy Report, 25(3): 1-27.

Hanafi, Z. 2008. The relationship between aspects of socio-economic factors and academic achievement. Jurnal Pendidikan Malaysia, 33: 95-105.

Ieiri, M.C.A., Kosaka, S., Tomitsuka, E. \& Umezaki, M. 2020. Factors affecting undernutrition among school children in Cebu, Philippines. Ecology of Food and Nutrition, 60(2):182-197.

Jomaa, L., Naja, F., Kharroubi, S. \& Hwalla, N. 2019. Prevalence and correlates of food insecurity among Lebanese households with children aged 4-18 years: Findings from a national crosssectional study. Public Health Nutrition, 22(2): 202-211.

Khan Khattak, M.M.A. \& Ali, S. 2010. Malnutrition and associated risk factors in pre-school children (2-5 years) in District Swabi (NWFP)-Pakistan. Journal of Medical Sciences, 10: 34-39.

Khor, G.L. 2003. Update on the prevalence of malnutrition among children in Asia. Nepal Medical Collaborator Journal, 5(2): 113-122.

Ligeve, S.N. \& Poipoi, D.M.W. 2012. The influence of child labour on academic achievement of primary school pupils in Suba and Homa-Bay Districts, Kenya. International Journal of Learning and Development, 2(4): 189-197.

Mamat, N., Sulaiman, N. \& Mesbah, S.F. 2019. Sociodemographic factors, food security and mental health status among mothers in Mentakab, Pahang, Malaysia. Malaysian Journal of Medicine and Health Sciences, 15(201): 47-52.

Maarof, M.I. 2018. Translation and Validation of Household Food Insecurity Access Scale (HFIAS) and Factors Associated with food insecurity among households with Children Aged Five to Six Years Old in Tumpat, Kelantan (Thesis). Pusat Pengajian Sains Perubatan, Universiti Sains Malaysia.

Ministry of Health Malaysia. 2005. National Nutrition Policy of Malaysia. Ministry of Health, Kuala Lumpur.

Ministry of Health Malaysia. 2000. Annual Report 2000. Ministry of Health, Kuala Lumpur.

Mutisya, M., Kandala, N.B., Ngware, M.W. \& Kabiru, C.W. 2015. Household food insecurity and nutritional status of urban poor children aged 6 to 23 months in Kenya Global health. BMC Public Health, 15(1): 1-10. 
Pei, C.S., Appannah, G. \& Sulaiman, N. 2018. Household food insecurity, diet quality, and weight status among indigenous women (Mah Meri) in Peninsular Malaysia. Nutrition Research and Practice, 12(2): 135-142.

Pek Geik, O.P., Sedek, R. \& Awang, A.F. 2016. Malnutrition and associated factors of aboriginal preschoolers in Gua Musang, Kelantan, Malaysia. Pakistan Journal of Nutrition, 15: 133-139.

Poh, B.K., Lee, S.T., Yeo, G.S., Tang, K.C., Noor Afifah, A.R., Siti Hanisa, A., Parikh, P., Wong, J.E., Ng, A. \& SEANUTS Study Group. 2019. Low socioeconomic status and severe obesity are linked to poor cognitive performance in Malaysian children. BMC Public Health, 19(Suppl 4): 541.

Rhoumah, A.M.O. 2016. Determinants of factors that affect poverty among coastal fishermen community in Malaysia. Journal of Economics and Finance, 7(3), 9-13.

Nursabrina, N.N.N.M.S, Asma', A., Kamarudin, K.S. \& Hayati, M.Y. 2018. Assessment of food insecurity and food coping strategies among fishermen household during monsoon in Terengganu, Malaysia. Malaysian Applied Biology, 47(6): 1-9.

Shariff, Z.M., Bond, J.T. \& Johnson, N.E. 2000. Nutrition and educational achievement of urban primary schoolchildren in Malaysia. Asia Pacific Journal of Clinical Nutrition, 9(4): 264-273.

Shariff, Z.M. \& Khor, G.L. 2008. Household food insecurity and coping strategies in a poor rural community in Malaysia. Nutrition Research and Practice, 2(1): 26-34.
Tai, S.W. \& Asma', A. 2018. Breakfast Consumption and its relationship with cognitive performance among fishermen's children in Terengganu. Malaysian Applied Biology, 47(4): 25-34.

Teh, S.C., Asma, A., Jan, J.H. \& Yusof, H.M. 2020. Assessment of food security, anthropometric and cognitive function among Orang Asli children in Pahang, Malaysia. IIUM Medical Journal Malaysia, 19(3): 81-91.

Tsai, M. \& Liu, F. 2013. Multigroup structural equation approach: Examing the Relationship among family socioeconomic status, parent-child interaction, and academic achievement using TASA samples. International Journal of Intelligent Technologies \& Applied Statistics, 6(4): 353-373.

Whye Lian, C., Wan Muda, W.A.M., Mohd Hussin, Z.A. \& Ching Thon, C. 2012. Factors associated with undernutrition among children in a rural district of Kelantan, Malaysia. Asia Pacific Journal of Public Health, 24(2): 330-342.

Wong, H.J., Moy, F.M. \& Nair, S. 2014. Risk factors of malnutrition among preschool children in Terengganu, Malaysia: A case control study. BMC Public Health, 14: 785.

Zhang, L. \& Yang, F. 2019. Food insecurity and school performance among the left-behind children in rural China: Depression and educational expectation as mediators. School Psychology International, 40(5): 510-524. 
